\title{
The shaping of the coherence function of resonate-and-fire neuron models
}

\author{
Sven Blankenburg ${ }^{1,2^{*}}$, Benjamin Lindner ${ }^{1,3}$, Susanne Schreiber ${ }^{1,2}$ \\ From Twenty Second Annual Computational Neuroscience Meeting: CNS*2013 \\ Paris, France. 13-18 July 2013
}

It is known that integrate-and-fire neurons act as low-pass filters on information [1], i.e. they preferentially encode information at low frequencies. However, many neurons cannot be described by such integrators, even qualitatively. Experiments show that in several areas of the mammalian brain single neurons display a resonance property in their subthreshold voltage dynamics, see for example $[2,3]$. Here, we study the information transmission of a currentbased resonate-and-fire neuron model [4] by means of the spectral coherence function. We use a stochastic input current (the Ornstein-Uhlenbeck process from statistical physics) to model a complex dynamical stimulus. We show by numerical simulations that resonate-and-fire neurons encode time-dependent stimuli preferentially at moderate frequencies, including their resonance frequency, i.e. the coherence function of this model shows a clear maximum as a function of frequency. This is in marked contrast to the low-pass coherence that is found for the pure subthreshold dynamics (in the absence of spiking) in spite of resonant filter properties. We discuss dynamical mechanisms that lead to the band-pass filtering of information in the spiking resonate-and-fire model.

\section{Acknowledgements}

This work was supported by grants from the BMBF (01GQ0901,01GQ1001A) and Deutsche orschungsgemeinschaft (SFB 618).

\section{Author details}

${ }^{1}$ Bernstein Center for Computational Neuroscience, Berlin, 10115, Germany. ${ }^{2}$ Institute for Theoretical Biology, Humboldt-Universität zu Berlin, Berlin, 10115, Germany. ${ }^{3}$ Institute for Physics, Humboldt-Universität zu Berlin, Berlin, 12489, Germany.

Published: 8 July 2013

\footnotetext{
* Correspondence: sven.blankenburg@physik.hu-berlin.de

${ }^{1}$ Bernstein Center for Computational Neuroscience, Berlin, 10115, Germany
}

Full list of author information is available at the end of the article

\section{References}

1. Vilela RD, Lindner B: A comparative study of different integrate fire neurons: spontaneous activity, dynamical response, and stimulusinduced correlation. Phys Rev E 2009, 80.

2. Hutcheon $B$, Yarom $Y$ : Resonance, oscillation and the intrinsic frequency preferences of neurons. TINS 2000, 23:216-222.

3. Erchova I, Kreck G, Heinemann U, Herz AVM: Dynamics of rat entorhinal cortex layer II/III cells: characteristics of membrane potential resonance at rest predict oscillation properties near threshold. Journal of Physiology 2004, 560:89-110.

4. Engel TA, Schimansky-Geier L, Herz AVM, Schreiber S, Erchova I: Subthreshold membrane-potential resonances shape spike-train patterns in the entorhinal cortex. J Neurophysiology 2008, 100:1576-1589.

\section{doi:10.1186/1471-2202-14-S1-P346}

Cite this article as: Blankenburg et al:: The shaping of the coherence function of resonate-and-fire neuron models. BMC Neuroscience 201314 (Suppl 1):P346. Submit your next manuscript to BioMed Central
and take full advantage of:

- Convenient online submission

- Thorough peer review

- No space constraints or color figure charges

- Immediate publication on acceptance

- Inclusion in PubMed, CAS, Scopus and Google Scholar

- Research which is freely available for redistribution

Submit your manuscript at www.biomedcentral.com/submit

\section{() Biomed Central}

\section{Biomed Central}

